\title{
Regular follow-up after curative resection of nonsmall cell lung cancer: a real benefit for patients?
}

\author{
U. Egermann*, K. Jaeggi", J.M. Habicht ${ }^{\ddagger}$, A.P. Perruchoud*, P. Dalquen\# ${ }^{\#}$, M. Solèr*
}

\begin{abstract}
Regular follow-up after curative resection of nonsmall cell lung cancer: a real benefit for patients? U. Egermann, K. Jaeggi, J.M. Habicht, A.P. Perruchoud, P. Dalquen, M. Solèr. (C)ERS Journals Ltd 2002.

ABSTRACT: Even though complete resection is regarded as the only curative treatment for nonsmall cell lung cancer (NSCLC), $>\mathbf{5 0} \%$ of resected patients die from a recurrence or a second primary tumour of the lung within 5 yrs. It remains unclear, whether follow-up in these patients is cost-effective and whether it can improve the outcome due to early detection of recurrent tumour.

The benefit of regular follow-up in a consecutive series of 563 patients, who had undergone potentially curative resection for NSCLC at the University Hospital, was analysed. The follow-up consisted of clinical visits and chest radiography according to a standard protocol for up to $\mathbf{1 0}$ yrs. Survival rates were estimated using the KaplanMeier analysis method and the cost-effectiveness of the follow-up programme was assessed.

A total of 23 patients $(6.4 \%$ of the group with lobectomy) underwent further operation with curative intent for a second pulmonary malignancy. The regular followup over a 10-yr period provided the chance for a second curative treatment to $3.8 \%$ of all patients.

The calculated costs per life-yr gained were 90,000 Swiss Francs. The costeffectiveness of the follow-up protocol was far above those of comparable large-scale surveillance programmes. Based on these data, the intensity and duration of the followup was reduced.

Eur Respir J 2002; 19: 464-468.
\end{abstract}

\author{
*Pulmonary Division, Dept of Internal \\ Medicine, ${ }^{\#}$ Institute of Pathology and \\ 'Dept of Cardiothoracic Surgery, Uni- \\ versity Hospital, Basel, Switzerland. \\ Correspondence: M. Solèr \\ St Claraspital \\ CH-4016 Basel \\ Switzerland \\ Fax: 41616858469 \\ E-mail: markus.soler@araspital.ch
}

Keywords: Cost effectiveness

lung cancer

post-operative follow-up

Received: April 272001

Accepted after revision October 92001
Surgery is the most appropriate treatment for early stage nonsmall cell lung cancer (NSCLC) [1]. Although 5-yr survival rates of $>60 \%$ can be achieved in selected groups of patients, overall, $>50 \%$ of those undergoing resection will still succumb to a recurrence [2]. As reported by the Lung Cancer Study Group, less than one-third of patients operated on for T1N0 disease were clinically disease-free for $>60$ months [3]. Thus, even after "complete" resection, patients are at risk of developing a recurrence. These recurrences, either distant, local or both, occur mainly within the first $5 \mathrm{yrs}$ after operation [4]. In addition, new pulmonary malignancies (metachronous second primary lung cancers (mSPLC)) may develop independently of the previous lung tumour. Metachronous second primary tumours, as defined by MARTINI and Melamed [5], have been identified in follow-up studies at a rate of $1 \%$ [6] and 5\% [7] per year. MARTINI and Melamed [5] reported a cumulative occurrence of mSPLC of $9 \%$ in patients after resection of stage I lung cancer.

Patients developing an mSPLC have to be treated differently from those relapsing from their first malignancy. For most recurrences treatment can only aim at palliation. For a few patients with a local recurrence after lobectomy and for some of the patients with an MSPLC, there is a chance to undergo a second potentially curative resection. In contrast to the relatively high number of mSPLCs observed in large-scale outcome studies, second curative resections are rare clinical events. To undergo such an operation, different criteria have to be fulfilled. First, the new malignancy has to have a resectable location, size and stage. Secondly, the patient's overall condition and lung function have to be adequate for a second resection of lung tissue.

There are few prospective studies on the efficacy of a standardized follow-up programme after resection of bronchial carcinomas, which could lead potentially to the detection of mSPLCs or recurrences at a treatable stage. In a retrospective study VIRGO et al. [8] showed no difference in survival between intensive and less-intensive follow-up in resected patients. Also, the health benefits of early detection of a second pulmonary malignancy have never been demonstrated convincingly. The aim of the present study was to assess the value and the cost-effectiveness of a regular follow-up programme for patients after curative resection of a NSCLC. The authors specifically tried to answer the following questions: 1) How many resectable mSPLCs can be detected in asymptomatic patients attending the follow-up programme? 2) Does a potentially curative re-operation result in improved survival? 3) How do the costs per life-yr gained 
(LYG) of this follow-up programme compare to other established therapies?

\section{Patients and methods}

\section{Study subjects}

Between January 1980-December $1997>615$ consecutive patients underwent a potentially curative resection for NSCLC at the University Hospital in Basel after standardized preoperative staging. All operations were performed by the same team of cardiothoracic surgeons. Perioperative mortality (within 30 days) was $2.6 \%(n=16)$. Six further patients died before the first follow-up visit at 3 months after operation. In this time span, early recurrences were found in 23 patients. Seven patients did not attend the first follow-up visit for unknown reasons. The studypopulation comprised those patients who attended the first follow-up visit 3 months after surgery in a clinically cancer-free state. This group of 563 patients (441 male, 122 female) had a median age of $64 \mathrm{yrs}$ (range: $28-85$ yrs). The resections performed were 340 lobectomies, 21 bilobectomies and 202 pneumonectomies. For further demographical description see table 1.

\section{Study design}

The follow-up visits took place every 3 months for up to $2 \mathrm{yrs}$, then every 6 months up to $5 \mathrm{yrs}$, followed by once a yr up to 10 yrs after surgery. Follow-up was performed by the family doctor or at the University Hospital's outpatients clinic, and consisted of a standardized patient history, physical examination and a chest radiography (after lobectomy or bilobectomy posterior-anterior and lateral, after pneumonectomy only posterior-anterior). Results were documented in a standardized questionnaire. All data were collected prospectively.

\section{Outcomes and end-points of study}

The major end-point of the study was the occurrence of an operable or inoperable reappearance

Table 1.-Demographics of study population

\begin{tabular}{lccc}
\hline Patients & Male & Female & Overall \\
\hline $\mathrm{n}$ & $441(78 \%)$ & $122(22 \%)$ & $563(100 \%)$ \\
Age (mean \pm SD) & $64.8 \pm 7.4$ & $60.1 \pm 10.7$ & $64.2 \pm 8.1$ \\
Histology & & & \\
$\quad$ Squamous-cell Ca & $272(62 \%)$ & $42(33 \%)$ & $314(56 \%)$ \\
$\quad$ Adeno-Ca & $93(21 \%)$ & $57(46 \%)$ & $146(26 \%)$ \\
$\quad$ Large cell Ca & $47(11 \%)$ & $10(8 \%)$ & $57(10 \%)$ \\
$\quad$ Bronchoalveolar Ca & $19(4 \%)$ & $14(11 \%)$ & $33(6 \%)$ \\
$\quad$ Undifferentiated & $10(2 \%)$ & $3(2 \%)$ & $13(2 \%)$ \\
$\quad$ NSCLC & 10
\end{tabular}

Data are presented as $\mathrm{n}(\%)$ unless otherwise stated. Ca: cancer; Adeno-Ca: adenocarcinoma; NSCLC: nonsmall cell lung cancer. of the bronchial malignancy. Minor end-points were defined as leaving the follow-up programme clinically cancer-free or unrelated to cancer. Approximately 70 patients did not reach a defined end-point and were still cancer-free under surveillance at the closing date of this study (May 1999). Recurrence or mSPLC could be detected either on a chest radiograph in an asymptomatic patient at a regular followup visit, or because of the onset of cancer-related symptoms in the interval between two visits. Diagnosis of a second primary lung cancer was based on the criteria defined by Martini and Melamed [5], which include: 1) different histologies of first and second tumour, or 2) in the case of identical histology there should be: a disease-free interval between both cancers of at least 2 yrs; the new malignancy should have originated from a cancer in situ; the first tumour and mSPLC occurred in different lobes, but no carcinoma was detectable in the lymph nodes common to both, and no extrapulmonary metastasis was present at the time of mSPLC diagnosis.

The duration of the disease free-interval between the date of first curative resection to the date of proven reappearance of a malignancy was calculated. In a second analysis the overall survival was assessed. Patients who left follow-up clinically cancer-free for different reasons or who are still under surveillance were censored at the time of their last visit. Informative censoring was excluded by comparing these patients with the remaining study population. A backward regression model was used to assess the relevant correlation of any factor with the duration of survival. It could be shown, that both groups had the same risk of developing a reappearance of a pulmonary malignancy.

\section{Analysis, cost-calculation and statistics}

The costs associated with the follow-up programme comprised the expenses of the clinical visit (120 Swiss Francs (SF)) and the chest radiographs (posterioranterior/lateral $180 \mathrm{SF}$, or posterior-anterior $170 \mathrm{SF}$ ). The cost of a second operation was estimated at 20,000 SF. Costs concerning further evaluation of suspicious findings were not included. Extra restaging costs were omitted.

Survival was calculated by the Kaplan-Meier method. Differences in survival between groups were determined by the log-rank test. Probability values of $p \leqslant 0.05$ were considered to be statistically significant. Multivariate regression analysis was used to assess the relevant correlation of age, sex, stage and histology of disease or any other factor and the duration of survival. To exclude any bias due to informative censoring, the Chi-squared test was used for analysis of between-group differences. Therefore the distributions of factors found to be of significant influence by the multivariate regression analysis were compared between censored and noncensored patients. 
Table 2. - Stages and survival

\begin{tabular}{lccc}
\hline & $\begin{array}{c}\text { Patients } \\
\mathrm{n}\end{array}$ & $\begin{array}{c}5 \mathrm{yr} \\
\text { survival } \%\end{array}$ & $\begin{array}{c}\text { Median survival } \\
\text { months }\end{array}$ \\
\hline Stage Ia & 112 & 55 & 66.0 \\
Stage Ib & 192 & 31 & 28.4 \\
Stage II & 173 & 13 & 22.5 \\
Stage III & 86 & 8 & 18.3 \\
\hline
\end{tabular}

\section{Results}

The study population consisted of 563 patients, who entered the follow-up programme in a clinically cancer-free state 3 months after operation (demographical description; tables 1 and 2). The median duration of follow-up was $<4$ yrs. A new malignancy or a recurrence was found in 239 patients (fig. 1). More than $70 \%$ of these occurred during the first 2 postoperative yrs, and $93 \%$ of them within $5 \mathrm{yrs}$. While 111 patients died cancer-free mainly during the first 2 yrs, 142 patients left the follow-up programme. The patients dropped out at a nearly constant rate of 11 patients $\cdot \mathrm{yr}^{-1}$. At the closing date of this study, 71 clinically cancer-free patients were still enrolled (fig. 1). Among the 563 patients who entered the follow-up programme, a total of 23 patients $(4.1 \%)$ underwent a second curative resection of an NSCLC (table 3 ). This group was representative of only $10 \%$ of those patients suffering from a reappearance of lung cancer.

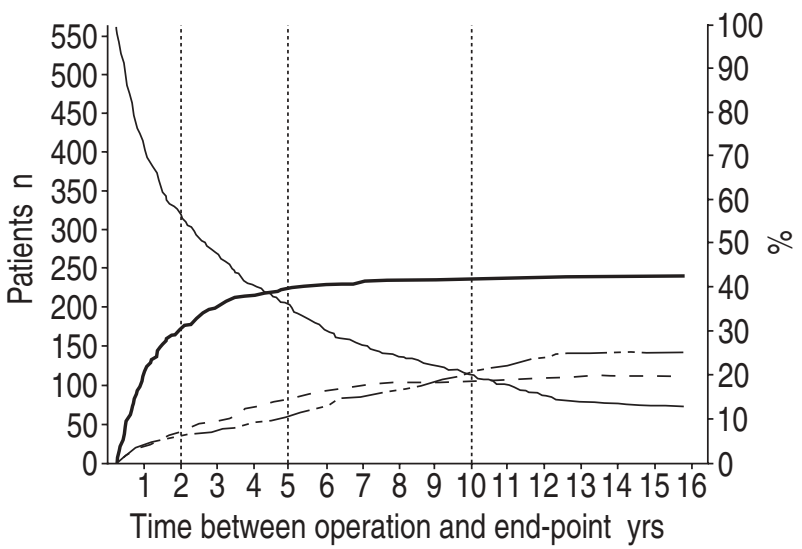

Fig. 1.- Time pattern of end-points as reached by 563 patients. Signs of bronchial carcinoma had re-developed in 239 patients (-); 342 patients were clinically-free of cancer; 142 patients were lost to follow-up ( $\left.-{ }_{-}-\right)$; 111 patients died $\left(--_{-}\right)$; 71 patients were still attending follow-up (-).

Whereas 21 tumours were clearly mSPLCs, completion pneumonectomies were performed in two cases of local recurrence. Fifteen of the re-operated patients $(2.6 \%$ of the study population) were detected at the regular follow-up visit, whereas the remaining eight tumours were found because of symptoms occurring between scheduled follow-up visits. Three of the 23 re-operated patients died within 30 days of the second thoracotomy (perioperative mortality $=13 \%$ ).

Table 3. - Demographics of patients undergoing re-operation

\begin{tabular}{|c|c|c|c|c|c|c|c|c|c|c|}
\hline \multirow{2}{*}{$\begin{array}{l}\text { Subject } \\
\text { no. }\end{array}$} & \multirow[t]{2}{*}{ Sex } & \multicolumn{4}{|c|}{ First operation } & \multirow{2}{*}{$\begin{array}{l}\text { Interval } \\
\text { months }\end{array}$} & \multicolumn{3}{|c|}{ Re-operation } & \multirow{2}{*}{$\begin{array}{c}\text { Survival after } \\
\text { re-operation } \\
\text { months }\end{array}$} \\
\hline & & $\begin{array}{l}\text { Age } \\
\text { yrs }\end{array}$ & Stage & Histology & $\begin{array}{c}\text { Operation } \\
\text { type }\end{array}$ & & Stage & Histology & $\begin{array}{l}\text { Operation } \\
\text { type }\end{array}$ & \\
\hline 1 & M & 67 & $\mathrm{Ib}$ & SQ & $\mathrm{L}$ & 6 & $\mathrm{IIb}$ & SQ & $\mathrm{CP}$ & 1 \\
\hline 2 & M & 63 & $\mathrm{Ia}$ & Balv & $\bar{L}$ & 6 & Ia & SQ & $\mathrm{L}$ & 59 \\
\hline 3 & M & 49 & $\mathrm{Ia}$ & $\mathrm{AD}$ & $\mathrm{L}$ & 18 & $\mathrm{IIb}$ & $\mathrm{AD}$ & $\mathrm{L}$ & 32 \\
\hline 4 & M & 63 & $\mathrm{Ib}$ & $\mathrm{AD}$ & $\mathrm{L}$ & 9 & $\mathrm{IIb}$ & $\mathrm{AD}$ & $\mathrm{CP}$ & 11 \\
\hline 5 & $\mathrm{~F}$ & 53 & $\mathrm{IIb}$ & $\mathrm{AD}$ & $\mathrm{L}$ & 5 & $\mathrm{IIb}$ & SQ & $\mathrm{CP}$ & 21 \\
\hline 6 & $\mathrm{M}$ & 53 & $\mathrm{Ib}$ & LA & $\mathrm{L}$ & 14 & Ia & LA & $\mathrm{L}$ & 16 \\
\hline 7 & $\mathrm{M}$ & 28 & $\mathrm{IIb}$ & LA & BiL & 11 & $\mathrm{Ia}$ & LA & $\mathrm{L}$ & $115^{\#}$ \\
\hline 8 & $\mathrm{M}$ & 58 & $\mathrm{IIb}$ & $\mathrm{AD}$ & $\mathrm{L}$ & 42 & $\mathrm{Ib}$ & AD & $\mathrm{L}$ & $76^{\#}$ \\
\hline 9 & $\mathrm{~F}$ & 49 & $\mathrm{Ib}$ & $\mathrm{AD}$ & $\mathrm{L}$ & 52 & $\mathrm{Ib}$ & $\mathrm{AD}$ & $\mathrm{L}$ & $55^{\#}$ \\
\hline 10 & $\mathrm{~F}$ & 50 & $\mathrm{Ib}$ & $\mathrm{AD}$ & $\mathrm{L}$ & 12 & IIIa & $\mathrm{AD}$ & $\mathrm{CP}$ & $92^{\#}$ \\
\hline 11 & $\mathrm{M}$ & 52 & $\mathrm{Ia}$ & Balv & $\mathrm{L}$ & 72 & $\mathrm{Ib}$ & $\mathrm{AD}$ & $\mathrm{L}$ & $19^{\#}$ \\
\hline 12 & $\mathrm{~F}$ & 74 & $\mathrm{Ib}$ & Balv & $\mathrm{L}$ & 29 & $\mathrm{Ib}$ & Balv & $\mathrm{L}$ & 3 \\
\hline 13 & $\mathrm{M}$ & 71 & $\mathrm{Ib}$ & SQ & $\bar{L}$ & 23 & $\mathrm{IIb}$ & $\mathrm{SQ}$ & $\mathrm{CP}$ & 1 \\
\hline 14 & $\mathrm{M}$ & 70 & $\mathrm{Ib}$ & SQ & $\mathrm{L}$ & 19 & $\mathrm{Ib}$ & SQ & $\mathrm{L}$ & 13 \\
\hline 15 & $\mathrm{M}$ & 64 & IIa & SQ & $\mathrm{L}$ & 18 & $\mathrm{Ib}$ & SQ & $\mathrm{CP}$ & $3^{\#}$ \\
\hline 16 & $\mathrm{M}$ & 71 & Ia & $\mathrm{AD}$ & $\mathrm{L}$ & 93 & $\mathrm{IIb}$ & Balv & $\mathrm{CP}$ & 51 \\
\hline 17 & M & 43 & $\mathrm{Ib}$ & SQ & $\mathrm{L}$ & 195 & Ia & SQ & $\mathrm{CP}$ & $19^{\#}$ \\
\hline 18 & $\mathrm{M}$ & 65 & $\mathrm{Ia}$ & $\mathrm{SQ}$ & $\mathrm{L}$ & 52 & $\mathrm{Ib}$ & $\mathrm{SQ}$ & $\mathrm{L}$ & 64 \\
\hline 19 & M & 66 & $\mathrm{Ib}$ & SQ & $\mathrm{L}$ & 29 & Ia & $\mathrm{SQ}$ & $\mathrm{CP}$ & 9 \\
\hline 20 & $\mathrm{M}$ & 73 & $\mathrm{Ib}$ & SQ & $\mathrm{L}$ & 30 & $\mathrm{IIb}$ & $\mathrm{SQ}$ & $\mathrm{CP}$ & 24 \\
\hline 21 & $\mathrm{M}$ & 56 & $\mathrm{IIb}$ & SQ & $\mathrm{L}$ & 26 & $\mathrm{IIa}$ & SQ & $\mathrm{CP}$ & $128^{\#}$ \\
\hline 22 & $\mathrm{M}$ & 67 & $\mathrm{Ib}$ & Balv & $\mathrm{L}$ & 65 & IV & Balv & $\mathrm{L}$ & 0 \\
\hline 23 & M & 66 & $\mathrm{IIa}$ & SQ & $\bar{L}$ & 19 & $\mathrm{IIa}$ & SQ & $\mathrm{CP}$ & $11^{\#}$ \\
\hline
\end{tabular}

M: male; F: female; SQ: sqamous cell cancer; Balv: bronchoalveolar cancer; AD: adenocarcinoma; LA: large cell cancer; L: lobectomy; BiL: bilobectomy; CP: completion pneumonectomy. ${ }^{\#}$ : patients still alive. Patients 1-15: tumour detected at follow-up visit. Patients 16-23: tumour detected between scheduled visits because of symptoms. 


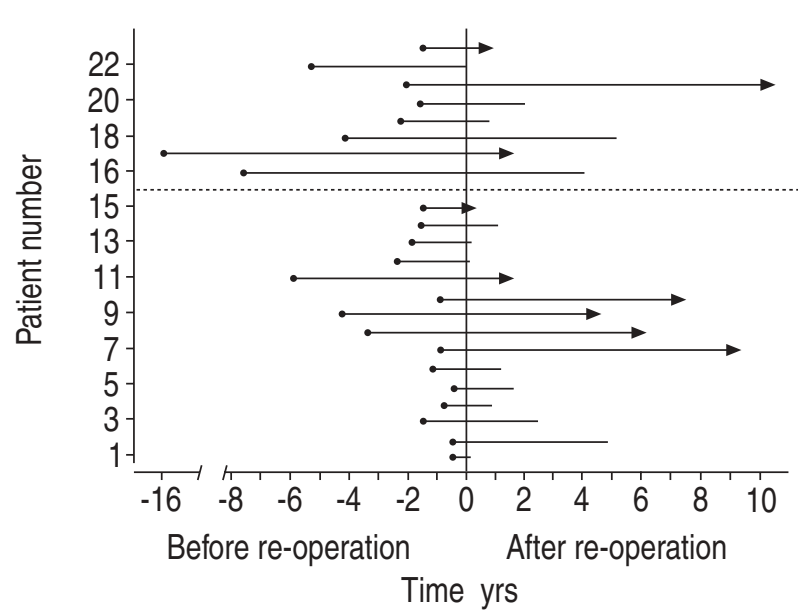

Fig. 2.- Interval between first and second operation and duration of survival after re-operation (indicated by solid vertical line). Asymptomatic detection of the second primary lung cancers during follow-up $(\mathrm{n}=15$; lower group below dashed line); symptomatic patients ( $\mathrm{n}=8$, upper group, above dashed line). Arrow heads indicate patients still alive.

Deaths occurred due to nonpulmonary causes (cardiac dysfunction, gastrointestinal bleeding, sepsis). Approximately one-half of the second resections occurred within 2 yrs of the first operation, however no correlation could be found between the time span between the first and second operation and the duration of survival after a second operation (fig. 2).

Survival rates are shown in table 4 . The overall group of 563 patients had a mean survival of $4.3 \mathrm{yrs}$. Functionally, only patients after lobectomy can be candidates for re-operation. Out of the group of 361 patients with lobectomy, 23 patients could be re-operated with curative intent. Comparing the survival of these 23 patients ( 65 months) with the remaining 338 patients (54 months), a nonsignificant difference was found. For the calculation of LYG, an estimated survival benefit of 9 months was used, which is clearly an overestimation. Taken together, all 23 re-operated patients gained a calculated benefit of $\sim 17$ additional life-yrs $(23 \times 9=207$ months $)$.

In this study population, a total of 5,464 follow-up visits were performed. The group of 361 patients with lobectomy attended 3,505 visits (300 SF per visit) and 23 re-operations $(20,000 \mathrm{SF}$ per operation) took place. The overall cost of follow-up for this group was more than 1,550,000 SF. Using the overestimated survival benefit, the costs per LYG were calculated at almost 90,000 SF.

\section{Discussion}

Only $4.1 \%$ of a large series of 361 patients undergoing lobectomy NSCLC gained a benefit from a follow-up programme. Regular clinical and radiographical examinations led to the discovery of a resectable metachronous primary lung cancer in 15 asymptomatic patients. The costs per LYGs with this follow-up programme were at least 90,000 SF.

Patients who undergo a curative resection for NSCLC are usually of advanced age, with some degree of chronic obstructive pulmonary disease, other smoking-related diseases and a relevant risk of developing a second respiratory malignancy. Clearly, these patients need follow-up, medical guidance and support postoperatively. A variety of different procedures have been proposed. Although no definitive guidelines exist for standard follow-up, most institutions see their patients for clinical visits and chest radiographs on each occasion [9], in a programme similar to that presented here. More intensive and costly programmes, including computed tomographyscans or bronchoscopy for detection of recurrences or mSPLCs [5], have not included any outcome-related results after treatment. This programme, therefore, is comparable to most established follow-up policies after resection of lung cancers $[10,11]$, and the overall rate of reoperable lung tumours $(4 \%)$ was within the expected range [12]. It was a surprise, however, that almost one-third of the tumours were detected because of symptoms, and not at the time of the scheduled follow-up visit, which further increases the costs per LYG of the programme.

To date, no regular follow-up programme has been shown to improve survival or quality of life of resected patients. Most groups focused on the detection of asymptomatic recurrences and could not report an improved survival [13]. Surgical treatment for tumour gives poor results [9], whilst a second primary lung cancer, detected at an early stage, can sometimes be resected. VIRGO et al. [14] were the first to estimate the cost of follow-up after potentially curative resection by analysis of Medicare files. There was no indication that a more intensive and costly follow-up could increase the survival or quality of life, a finding similar to a study by Younes et al. [15].

In the USA, $\$ 50,000 \cdot \mathrm{LYG}^{-1}$ is regarded as the upper limit of acceptable cost-effectiveness, while other countries report even lower limits [16]. Therefore, the costs per LYG in this programme of at least $90,000 \mathrm{SF}(\$ 56,000)$ seems high. Compared to breast

Table 4. - Survival times of different subgroups

\begin{tabular}{lccc}
\hline Groups of patients & Patients n & $\begin{array}{c}\text { Median (95\% CI) } \\
\text { survival time months }\end{array}$ & SE days \\
\hline All resected patients & 563 & $53(45-51)$ & 116 \\
After pneumonectomy & 201 & $45(33-58)$ & 187 \\
After lobectomy & 361 & $56(46-67)$ & 161 \\
After lobectomy without reoperation & 338 & $54(44-64)$ & 150 \\
All reoperated patients & 23 & $65(33-97)$ & 486 \\
\hline
\end{tabular}

CI: confidence interval. 
cancer screening $\left(\$ 19,000 \cdot \mathrm{LYG}^{-1}\right)$ [17] or postoperative management of colon cancer $\left(<\$ 10,000 \cdot \mathrm{LYG}^{-1}\right)$ [18], these costs are in the dimension of renal haemodialysis $(\$ 64,000)$ [19]. Therefore, the authors no longer advocate this intensive programme. However, most of these patients see their family physicians regularly, often at even shorter intervals for other coexisting diseases. Therefore, the visits for the followup may coincide with these visits, leading to an overestimate of the costs for the programme. A change of visit-frequency in the established programme to 6-monthly intervals for the first 5 yrs would almost halve the number of radiographs $(3,505$ versus 1,720$)$ and reduce the costs of the present programme by one-third. With this schedule, the detection of the mSPLC in only six of the 15 asymptomatic patients would have been postponed by $<90$ days. These six patients probably would have been still operable after that time.

From the economic point of view the nihilism of many physicians towards regular follow-up is understandable. This study provides sufficient data to answer the question of cost-effectiveness of a regular postoperative follow-up programme for the first time. In view of its high costs and limited benefits, the authors will proceed with a follow-up programme of visits and radiographs every 6 months for the first 5 yrs.

\section{References}

1. van Rens MT, Brutel De La Riviere A, Elbers HR, van Den Bosch JM. Prognostic assessment of 2361 patients who underwent pulmonary resection for non-small cell lung cancer, stage I, II, and IIIa. Chest 2000; 117: 374-379.

2. Clifton F, Mountain MD. Revisions in the international system for staging lung cancer. Chest 1997; 111: 1711-1717.

3. Thomas PA, Rubinstein L. Malignant disease appearing late after operation for T1N0 non-small-cell lung cancer. J Thorac Cardiovasc Surg 1993; 106: 10531058.

4. Martini N, Bains MS, Burt ME, et al. Incidence of local recurrence and second primary tumors in resected stage I lung cancer. $J$ Thorac Cardiovasc Surg 1995; 109: 120-129.
5. Martini N, Melamed MR. Multiple primary lung cancers. J Thorac Cardiovasc Surg 1975; 70: 606-611.

6. Johnson BE. Second lung cancers in patients after treatment for an initial lung cancer-review. J Natl Cancer Inst 1998; 90: 1335-1345.

7. Deschamps C, Pairolero PC, Trastek VF, Payne WS. Multiple primary lung cancers. $J$ Thorac Cardiovasc Surg 1990; 99: 769-778.

8. Virgo KS, McKirgan LW, Caputo MCA, et al. Posttreatment management options for patients with lung cancer. Ann Surg 1995; 222: 700-710.

9. Pieters RS, Krutchik AN, Kane GC, Freidland DM. What should be the routine follow-up after definitive therapy of localized lung cancer? Semin Oncol 1996; 23: 15-28.

10. Ginsberg RJ, Goldberg M, Waters PF. Surgery for nonsmall cell lung cancer. In: Roth JA, Ruckdeschel JC, Weisenburger TH, eds. Thoracic Oncology. Philadelphia, WB Saunders, 1989; pp. 123-162.

11. Edelman MJ, Meyers FJ, Siegel D. The utility of follow-up testing after curative cancer therapy. $J$ Gen Intern Med 1997; 12: 318-331.

12. Adebonojo SA, Dennis MM, Danby CA. The results of modern surgical therapy for multiple primary lung cancers. Chest 1997; 112: 639-701.

13. Walsh GL, $\mathrm{O}^{\prime}$ Connor $\mathrm{M}$, Willis $\mathrm{KM}$, et al. Is follow up of lung cancer patients after resection medically indicated and cost effective? Ann Thorac Surg 1995; 60: $1563-1572$.

14. Virgo KS, Naunheim KS, McKirgan LW, Kissling ME, Lin JC, Johnson FE. Cost of patient follow-up after potentially curative lung cancer treatment. J Thorac Cardiovasc Surg 1996; 112: 356-363.

15. Younes RN, Gross JL, Deheinzelin D. Follow-up in lung cancer. Chest 1999; 115: 1494-1499.

16. Schrag D. Defining optimal treatment for stage II colon cancer: Does decision analysis help? Gastroenterology 1999; 117: 1005-1008.

17. Leivo T, Sintonen H, Tuominen R, Hakama M, Pukkala E, Heinonen OP. The cost-effectiveness of nationwide breast carcinoma screening in Finland, 1987-1992. Cancer 1999; 86: 638-646.

18. Michel P, Merle V, Chiron A, et al. Postoperative management of stage II/III colon cancer: A decision analysis. Gastroenterology 1999; 117: 784-793.

19. Evans WK, Will BP, Berthelot JM, Wolfson MC. The economics of lung cancer management in Canada. Lung Cancer 1996; 14: 19-29. 